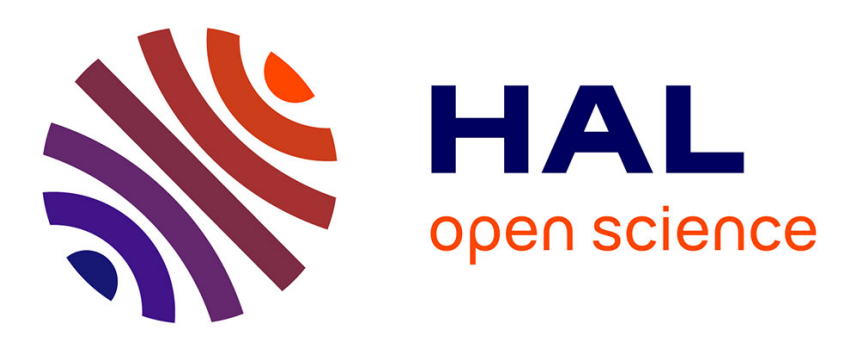

\title{
Morphogenetic analysis of the phenotypic variability of the architectural unit of Hydrangea macrophylla
}

Gilles Galopin, Jean-Claude Mauget, Philippe Morel

\section{To cite this version:}

Gilles Galopin, Jean-Claude Mauget, Philippe Morel. Morphogenetic analysis of the phenotypic variability of the architectural unit of Hydrangea macrophylla. Annals of Forest Science, 2010, 67 (3), 11 p. 10.1051/forest/2009115. hal-00742001

\section{HAL Id: hal-00742001}

\section{https://institut-agro-rennes-angers.hal.science/hal-00742001}

Submitted on 31 May 2020

HAL is a multi-disciplinary open access archive for the deposit and dissemination of scientific research documents, whether they are published or not. The documents may come from teaching and research institutions in France or abroad, or from public or private research centers.
L'archive ouverte pluridisciplinaire HAL, est destinée au dépôt et à la diffusion de documents scientifiques de niveau recherche, publiés ou non, émanant des établissements d'enseignement et de recherche français ou étrangers, des laboratoires publics ou privés.

$$
\text { Copyright }
$$




\title{
Morphogenetic analysis of the phenotypic variability of the architectural unit of Hydrangea macrophylla
}

\author{
Gilles GALOPIN ${ }^{1 *}$, Jean-Claude MAUGET ${ }^{2}$, Philippe MOREL $^{1}$ \\ ${ }^{1}$ UMR SAGAH A 462, Sciences Agronomiques Appliquées à l'Horticulture, INRA, Agrocampus Ouest - Université d'Angers, \\ 42 rue Georges Morel, B.P. 57, 49071 Beaucouzé, France \\ ${ }^{2}$ UMR GenHort A 1259, INRA, Agrocampus Ouest, Université d’Angers, 42 rue Georges Morel, B.P. 57, 49071 Beaucouzé, France
}

(Received 12 May 2009; accepted 5 September 2009)

Keywords:

Hydrangea macrophylla / phenotypic variability / morphogenesis / organogenesis / floral initiation / dormancy / architectural unit
Mots-clés :

Hydrangea macrophylla / variabilité phénotypique / morphogenèse /

organogenèse /

initiation florale /

dormance /

unité architecturale

\begin{abstract}
- Hydrangea macrophylla is a ligneous plant that has attracted the attention of many plant breeders and agronomists for the purpose of enhancing its phenotypic plasticity. However, this plasticity was always exploited empirically.

- Can this plasticity be assessed by a more scientific approach? In this work, the phenotypic variation is analysed via a description of the different development sequences of the plant and by exposing the plant to different contrasted environments.

- The architectural unit consists of two morphogenetic units: the Vegetative Unit (VU) and the Vegetative and Floral Unit (VFU). They result in four successive development sequences: an organogenetic phase accompanied by continuous growth (sequence A), floral transformation (sequence B), dormancy (sequence C) and flower bloom (sequence D). Under the effect of environmental factors, the formation of the mixed terminal bud (sequence B) provides a considerable source of spatial variability, whereas the absence or presence of dormancy (sequence C) is responsible for a source of temporal variation.

- The in-depth description of the architectural unit with its morphological components and the characterisation of the four development sequences provide a necessary scientific basis to identify environmental effects on plant development and for the integrated use of its plasticity.
\end{abstract}

Résumé - Analyse morphogénétique de la variabilité phénotypique de l'unité architecturale d'Hydrangea macrophylla.

- Hydrangea macrophylla est une plante ligneuse présentant une grande plasticité phénotypique qui a suscité l'intérêt de nombreux sélectionneurs et agronomes. Celle-ci a cependant toujours été exploitée de façon empirique.

- Peut-on évaluer cette plasticité par une approche plus scientifique? Dans ce travail, la variation phénotypique est analysée par une description fine des différentes séquences de développement de la plante et par l'exposition de la plante à des environnements contrastés.

- L'unité architecturale est composée de deux unités de morphogenèse : l'Unité Végétative et l'Unité Végétative et Florale. Elles résultent de quatre séquences de développement successives : une phase d'organogenèse accompagnée d'une croissance continue (séquence A), la transformation florale (séquence B), la dormance (séquence C) et l'épanouissement floral (séquence D). Sous l'effet des facteurs environnementaux, la formation du bourgeon mixte terminal (séquence B) offre une source de variabilité spatiale forte alors que l'absence ou la présence d'une dormance (séquence C) est à l'origine d'une source de variation temporelle.

- La description fine de l'unité architecturale avec ses composantes morphologiques et la caractérisation des quatre séquences de développement est une base scientifique nécessaire pour identifier et localiser les effets de l'environnement sur le développement de la plante et pour l'exploitation raisonnée de sa plasticité.

\footnotetext{
*Corresponding author: gilles.galopin@agrocampus-ouest.fr
} 


\section{INTRODUCTION}

Hydrangea macrophylla is a ligneous plant native to wet Japanese woodlands. It has bushy architecture with branched axes and terminal sexuality. The first flowering axis is the basis for the construction of the bush; it's the architectural unit. After its terminal flowering, it branches in the distal position. This flowering axis is repeated or partially reiterated on four or five branching orders. The survival of the bush is ensured by the development of new proximal axes (total reiteration), close to the stem and that will follow the same development process (Fig. 1) (Galopin, 1995). The bush is therefore composed of architectural units with a limited lifespan that renew themselves and disappear as a result of natural pruning.

The floral axis develops over two years of growth. Continuous plant growth over the first year ensures the formation of the stem. This is followed by the floral transformation that is morphologically identifiable by the formation of a mixed bud, composed of scale leaves, leaf primordia and the inflorescence (Galopin et al., 2008; Littlere and Strømme, 1975; Uemachi and Nishio, 2000). This floral transformation takes place at the end of the summer in temperate climates. It is followed by the onset of bud dormancy that requires cooler temperatures to restore growth capability (Fuchigami and Wisniewski, 1997; Wallerstein, 1981). The second year, terminal flowering is ensured by the elongation of all of the vegetative and floral organs preformed in the mixed bud. This flowering axis is defined as the architectural unit in H. macrophylla. Sequential branchings that develop are reiterations (Caraglio, 1986; Edelin, 1986) of the architectural unit (Galopin, 1995). They are considered to be total reiterations when they originate from the stem or are in a proximal position, and partial reiterations when they are in a distal position (Fig. 1). Within a horticultural context, these reiterations can be brought about by pruning to generate traumatic branchings that modify the architectural structure of the bush.

Many varietal selections have been made from H. macrophylla, used for a very long time as an ornamental plant in its native country. It was then introduced into Europe in the 18th century in pedoclimatic regions favourable to its development, with humic soils and mild and humid climates (Sauvage and Chevalier, 1943). The development of its ornamental use over time, first as a garden plant and then as a potted house plant (branched or single-stemmed) and, finally, as a cut flower, has made it possible to demonstrate the wide range of spatial and temporal variability of its development (Bailey, 1989; Cayeux, 1937; Sieben, 1978). This considerable development in the ornamental use of $H$. macrophylla was made possible thanks to the great number of agronomic experiments carried out over the past $30 \mathrm{y}$. They have shown the influence of water restriction (Cameron et al., 2006; Morel, 2001), root volume restriction (Yeh and Chiang, 2001), temperatures (Adkins et al., 2003; Bailey and Weiler, 1984; Post, 1942; Vidalie, 1986), photoperiod (Guo et al., 1995; Morita et al., 1980; Shanks et al., 1986), light intensity (Bailey et al., 1987; Dugardin and Balemans, 1991; Rusch et al., 1986), plant growth regulators (Bailey et al., 1986; Joustra, 1989; Morita and Osuka, 1981) and relative air humidity (Codarin et al., 2006) on plant de-

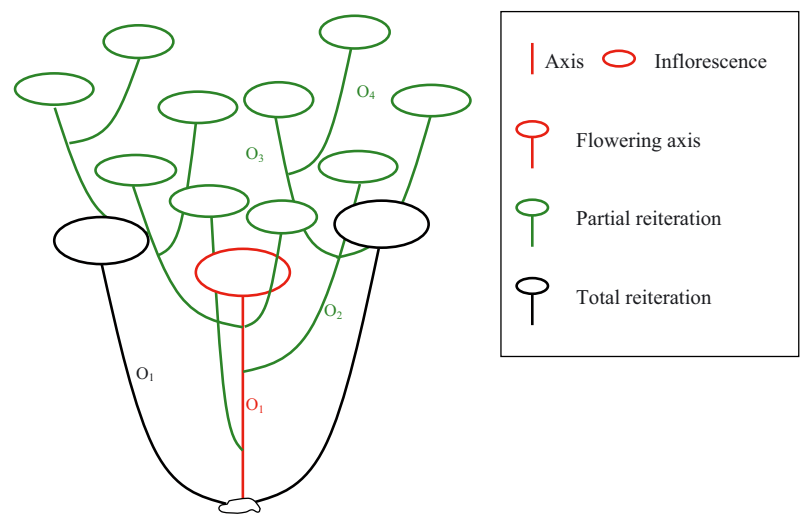

Figure 1. Bushy architecture of Hydrangea macrophylla; flowering axis (architectural unit), partial reiteration, total reiteration and branching orders $\mathrm{O}_{\mathrm{x}}$. (A color version of this figure is available at www.forest.org.)

velopment. These experiments made it possible to capitalise on knowledge about existing interactions between plant development and certain environmental factors. The experimental approach used until now has limits that prevent it from taking maximum advantage of plant plasticity for the purpose of generating new forms. In fact, the integrated use of environmental factors as a means to influence the orientation of plant morphogenesis requires phenotypic variations to be analysed beforehand, taking all of the plant's components and their origin into account during the different phases of its development. However, this analysis is not possible given our current level of knowledge.

In this study, we propose an in-depth description of the architectural unit of H. macrophylla with its different morphological components and the various development sequences responsible for its morphogenesis. We then identify potential sources of variability of the spatio-temporal development of the architectural unit by analysing plant development in three different climatic environments: under natural conditions, in the greenhouse and in the growth chamber. This allows us to discuss plant plasticity in relation to photoperiod and temperature.

\section{MATERIALS AND METHODS}

\subsection{Plant material}

The experiment was carried out on $H$. macrophylla cv Leuchtfeuer. This deep pink genotype with globular inflorescence presents a wide phenotypic variability since it is used as an ornamental plant outdoors, indoors in pots and for cut flowers. Young plants were obtained from juvenile cuttings, cloned and produced by mother microplant culture (Galopin et al., 1996). Cuttings consisted of two pairs of leaves, left to root in $33 \mathrm{~mm}$ diameter alveolated sheets filled with pre-moistened perlite. They were placed on subirrigation tables in a greenhouse $\left(\mathrm{T}^{\circ}: 21 \pm 2{ }^{\circ} \mathrm{C}\right.$; photoperiod: $\left.16 \mathrm{~h} ; R H>85 \%\right)$. Young plants were repotted one month after the initial cutting. 
a)

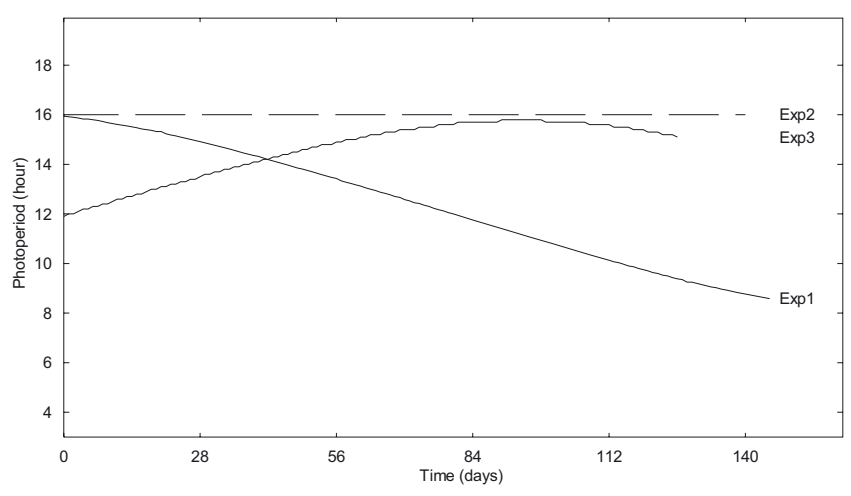

b)

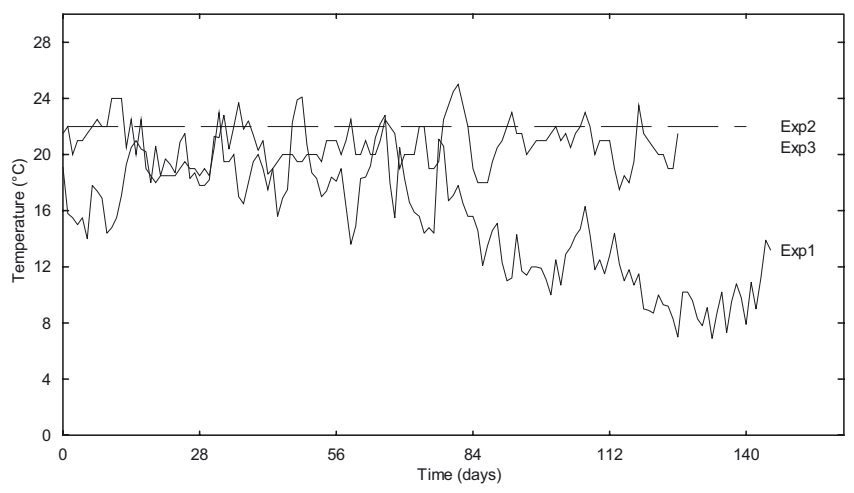

Figure 2. Evolution of photoperiod (a) and temperature (b) conditions for three experimental conditions over the first $145 \mathrm{~d}$ of growth.

\subsection{Experimental design}

The experiment took place in Angers, France (47 $33^{\prime} 37 \mathrm{~N}$, $00^{\circ} 18^{\prime} 44 \mathrm{~W}$, altitude: $59 \mathrm{~m}$ ) using three different experimental designs: the main design (Exp1) under which dynamic and destructive observations made it possible to define the different phases of development, and two other designs (Exp2 and Exp3) in which dynamic and non-destructive measurements were made.

Experience 1: The young plants were repotted on 17 July (Week 29: W29), in 1-litre pots, in a substrate consisting of peat $(60 \%)$ and perlite (40\%) and placed outdoors under natural climatic conditions with a naturally decreasing photoperiod and temperature (Tab. I and Fig. 2). The decision to grow the plants outdoors is related to the fact that the development of $H$. macrophylla is very well adapted to the natural climatic conditions of the Angers region. The plants were then transferred to a cold chamber maintained at $2{ }^{\circ} \mathrm{C}$ for 15 weeks to artificially break the dormancy (W50 to W13), and then placed in a greenhouse until flower bloom (W13 to W22). The minimum air temperature was $20{ }^{\circ} \mathrm{C}$ in the greenhouse, with ventilation when the temperature reached $24{ }^{\circ} \mathrm{C}$. Relative humidity was maintained at $70{ }^{\circ} \mathrm{C}$ with a fine mist system. Plants were submitted to a photon flux density of $90 \mu \mathrm{E} \mathrm{s}^{-1} \mathrm{~m}^{-2}$ for $16 \mathrm{~h}$ /day using $400-\mathrm{W}$ highpressure sodium vapour lamps. The sample consisted of 240 plants.

Experience 2: The young plants were repotted on 4 January (W1), in 1-litre pots filled with perlite (100\%), and placed in a growth chamber. The daytime temperature was $24{ }^{\circ} \mathrm{C}$, the night-time temperature $22{ }^{\circ} \mathrm{C}$ (Tab. I and Fig. 2), the relative humidity $80 \%$, with a photon flux density of $70 \mu \mathrm{E} \mathrm{s}^{-1} \mathrm{~m}^{-2}$ for $16 \mathrm{~h} /$ day using fluorescent tubes. The sample consisted of five plants.

Experience 3: The young plants were repotted on 19 March (W12), in 5.3-litre planters filled with perlite (100\%), and placed in a greenhouse. Plants were submitted to a long natural photoperiod (greater than $12 \mathrm{~h}$ ). The room temperature varied from 18 to $24{ }^{\circ} \mathrm{C}$ (Tab. I and Fig. 2). The sample consisted of 20 plants.

The photoperiod and temperature conditions applied were chosen to favour different developments. While maintaining semi-controlled conditions, they were defined on the basis of the work of Post (1942), Bailey and Weiler (1984) and Shanks et al. (1986), who reported that temperatures below $18{ }^{\circ} \mathrm{C}$ and a short photoperiod are favourable to floral transformation, whereas temperatures above $22{ }^{\circ} \mathrm{C}$ and a long photoperiod are unfavourable.

In the three different experiments, plants were irrigated by localised fertigation with a nutrient solution consisting of the following major elements in mol.M-3: $4.8 \mathrm{NO}^{-}$; $1.08 \mathrm{H}_{2} \mathrm{PO}^{-}$; $0.12 \mathrm{HPO}^{-}$; $0.3 \mathrm{SO}^{-} ; 0.32 \mathrm{Cl}^{-} ; 2.4 \mathrm{~K}^{+} ; 0.08 \mathrm{Na}^{+} ; 1.04 \mathrm{Ca}^{++} ; 0.44 \mathrm{Mg}^{++}$; $0.8 \mathrm{NH}^{+} ; \mathrm{pH} 6.5$.

\subsection{Measurements and expression of results}

Analysis of the vegetative and floral organogenesis was carried out on the basis of destructive observations and measurements once a week on five plants. It was carried out under Exp1 and on three morphological components: the number of leaf primordia in the bud, the 
Table I. Experimental conditions for the three trials (Exp1, Exp2 and Exp3).

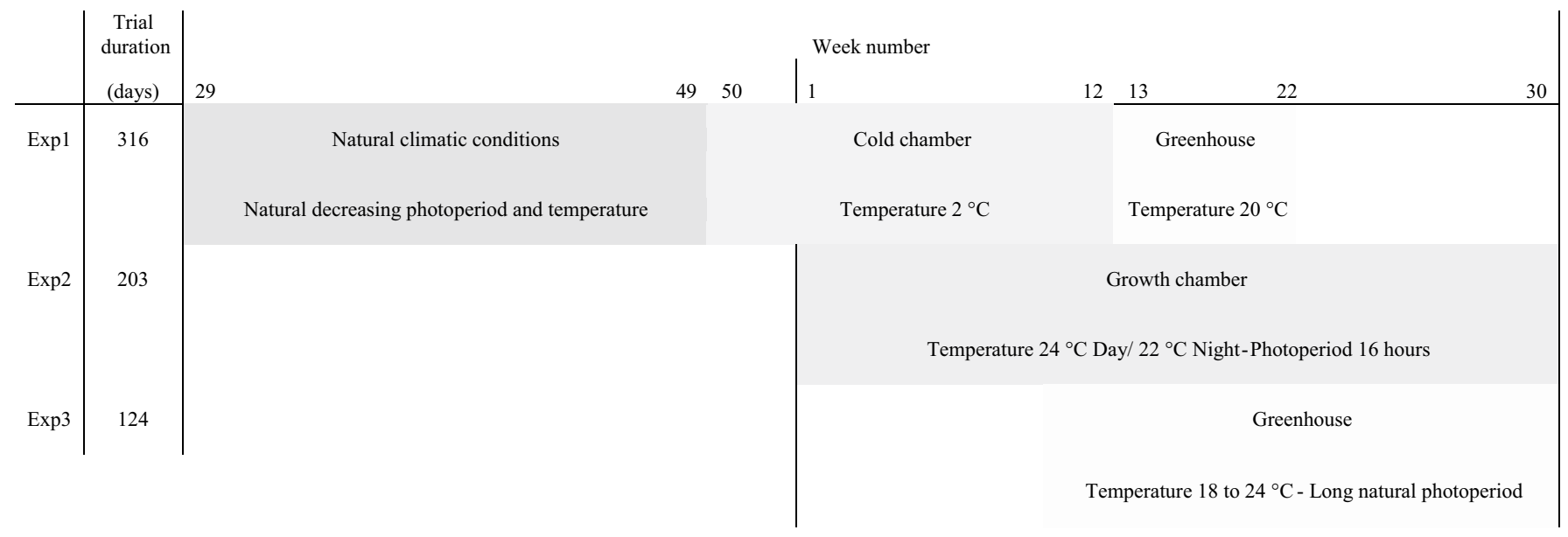

number of phytomers and the floral stage. The latter is ranked from 1 to 7 in relation to the stage of organogenesis reached (1: vegetative stage; 2: one inflorescent meristematic dome; 3 : three meristematic domes; 4: nine meristematic domes; 5: a large number of inflorescent meristematic domes; 6: differentiation of floral primordia; 7: differentiation of floral organs) (Galopin et al., 2008), and from 8 to 14 in relation to the degree of floral bloom (8: inflorescence visible; 9: sepal detachment; 10: beginning of sepal coloration; 11, 12, 13 and 14 correspond, respectively, to $25,50,75$ and $100 \%$ of sepal coloration). These measurements allowed us to calculate the duration of true leaf initiation, known as the true plastochron, which corresponds to the time separating the formation of the two successive leaf primordia by the meristem.

Vegetative and floral growth was quantified by means of a weekly measurement made for the three different experiments, with 30 plants for Exp1 and five plants for Exp2 and Exp3. The measurement involved on three morphological components: the internodes (number and length), the leaves (length) and the inflorescence (diameter). The length of the leaf $(L)$ allowed us to calculate the leaf area $(A)$ according to an allometric relationship $\left(A=0.5338 L^{2} 2-0.9315 L+1.1568\right.$; $\left.R^{2}=0.9842\right)$. These measurements made it possible to calculate the duration of apparent leaf initiation, known as the apparent plastochron, which corresponds to the time separating the emergence of two successive pairs of leaves. This calculation is made when the leaf blade has reached half of its adult size.

A morphological diagram was drawn up for the three experiments on all of the plants at the end of the tests. It includes leaf length, internode length and the diameter of the inflorescence.

Statistical analyses were made on the basis of the calculation of the mean and of the confidence interval at $5 \%$. Gnuplot software was used to plot the results.

\section{RESULTS}

\subsection{Evolution of the vegetative and floral organogenesis of the architectural unit}

Apical vegetative organogenesis is characterised by the evolution of the number of phytomer primordia in the bud and the evolution of the number of visible phytomers making up the axis (Fig. 3). The number of phytomer primordia in the bud is constant up to the 56th $\mathrm{d}$ of growth and equal to $3.29 \pm 0.23$. It then increases up to day 145 when it reaches the value of 8 . This accumulation of the primordia at the apical level leads to the formation of a bud. Moreover, the number of visible phytomers increases linearly until the 56th $\mathrm{d}$. It then remains stable until the $252 \mathrm{nd} \mathrm{d}$ and subsequently increases very rapidly from the 252 nd to the 276 th $\mathrm{d}$ when it reaches a final value of $19.80 \pm 1.22$. The cumulative total of the phytomer primordia and the visible phytomers allows us to calculate, during the linear phase of growth, up to day 56, the true plastochron, which is equal to $7.67 \mathrm{~d}$. From the 56th to the 145th d, the true plastochron increases according to the equation curve, $y=15.08 \times 0.11(R 2=0.99 ; y=$ number of primordia; $x=$ number of days) and with an average value of $18.94 \mathrm{~d}$ (Fig. 3). Inflorescential organogenesis begins during this same period. It rapidly evolves from the $0.4 \pm 0.55$ to the $5.2 \pm 0.45$ stage from the 76th to the $103 \mathrm{rd} \mathrm{d}$, and then more slowly from the 5.2 to the 6.0 stage from the 103rd to the 145th d. After an interruption during the transition to the cold chamber, floral organogenesis continues until the end of growth, up to the $13.5 \pm 0.51$ stage (Fig. 3).

The analysis of vegetative and floral organogenesis enables us to identify four phases: a first phase, up to the 56th d, with continuous vegetative organogenesis, a constant number of phytomer primordia at the apical level and, therefore, an apparent plastochron equal to the true plastochron; the second phase, from the 56th d to the 140th d, with the continuation of vegetative organogenesis, the end of the emergence of new leaf pairs, inflorescential organogenesis and, thus, the formation of a mixed bud; the third phase, corresponding to the cold treatment at $2{ }^{\circ} \mathrm{C}$ (from the 145th to the 258th d); and the fourth phase, with the emergence of preformed leaves and the continuation of inflorescential organogenesis until floral bloom (from the 258th to the 316th d) (Fig. 3).

\subsection{Dynamic analysis of the growth of the organs in the architectural unit}

Under experimental conditions (Exp1), the growth of the axis, measured by its length, is continuous for the first $56 \mathrm{~d}$ 


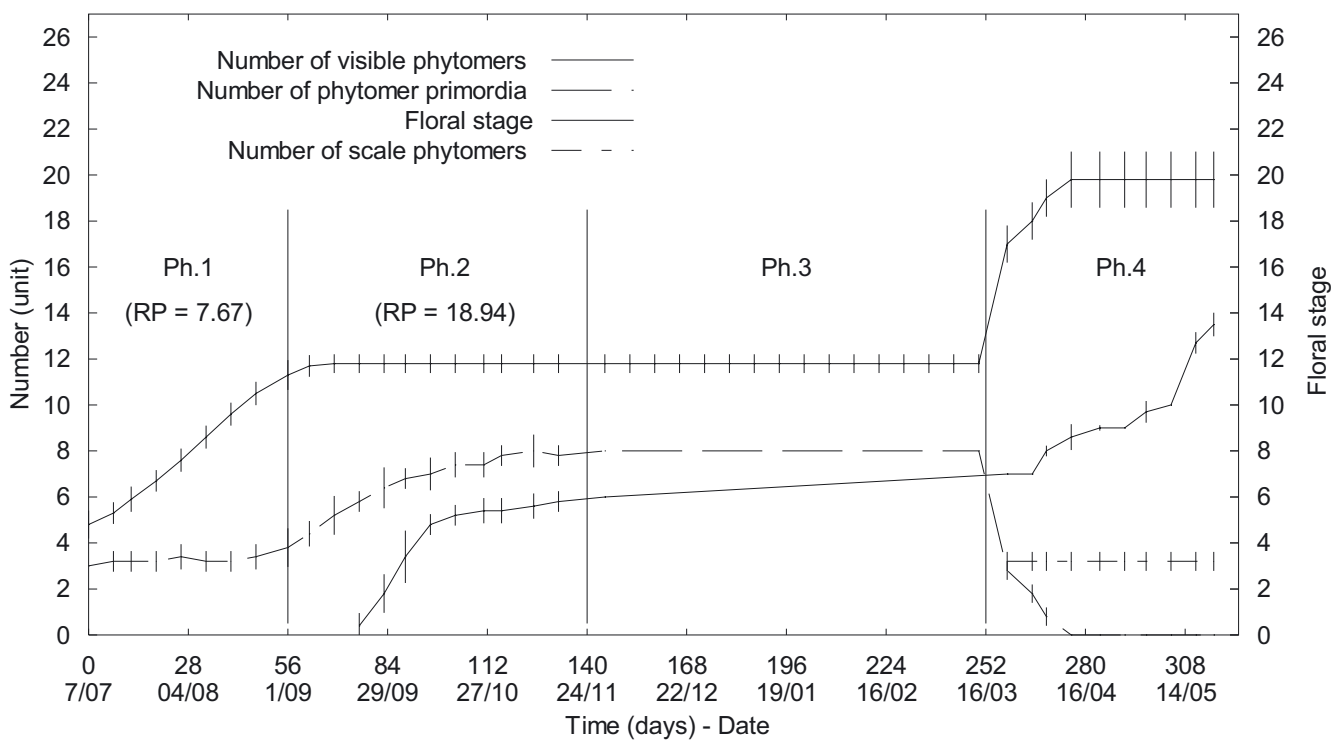

Figure 3. Evolution of vegetative and floral organogenesis at the apical level during the formation of the architectural unit (Exp1). Number of phytomer primordia in the terminal bud; number of visible phytomers; number of scale phytomers; floral stage; real plastochron: RP (in days); differentiation of four development stages: $\mathrm{Ph}$.

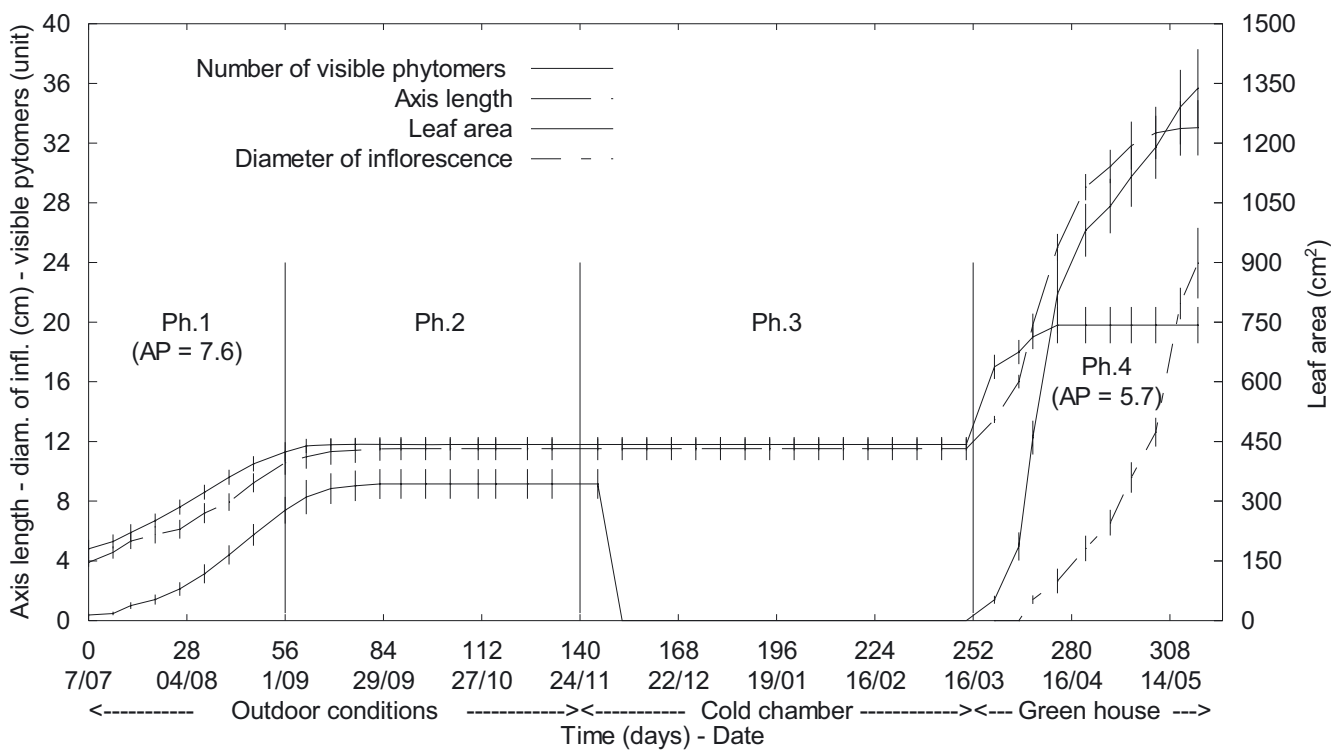

Figure 4. Growth dynamics of the different organs during the formation of the architectural unit (Exp1). Number of visible phytomers; axis height $(\mathrm{cm})$, leaf area $\left(\mathrm{cm}^{2}\right)$ and diameter of inflorescence $(\mathrm{cm})$; apparent plastochron: AP (in days); differentiation of the four development phases: $\mathrm{Ph}$.

of growth with an average growth rate of $1.2 \mathrm{~mm}$ per day (Fig. 4). It then stops until it is removed from the cold chamber. At that time, growth, as assessed by the elongation of the preformed internodes in the bud, is considerable (an average of $3.37 \mathrm{~mm}$ per day), with a sigmoid growth equation curve, $y=-3.18 x^{2}+58.08 x+67.33$ and $R^{2}=0.98$ (Fig. 4). The inflorescence gradually blooms as the axis grows. The evolution of the leaf area has the same growth dynamics as the axis length with an increase until the 60th $\mathrm{d}$, followed by stabilisation. The total leaf surface is then $343.44 \pm 37.28 \mathrm{~cm}^{2}$ (Fig. 4). The tran- sition to cold temperatures $\left(2{ }^{\circ} \mathrm{C}\right)$ causes the leaves to fall off within $15 \mathrm{~d}$. When the plant is taken out of the cold chamber, the growth of preformed leaves in the bud makes it possible to obtain a new leaf area of $1338 \pm 97.90 \mathrm{~cm}^{2}$ within $66 \mathrm{~d}$, with pairs of highly heterogeneous variable adult-size leaves (from 12.7 to $19.7 \mathrm{~cm}$ ), depending on the rank of the phytomer considered. The growth of the inflorescence begins $15 \mathrm{~d}$ after the plant has been removed from the cold chamber; its diameter reaches $23.95 \pm 2.36 \mathrm{~cm}$ in $50 \mathrm{~d}$, at the stage where all of the sepals are coloured (Fig. 4). 


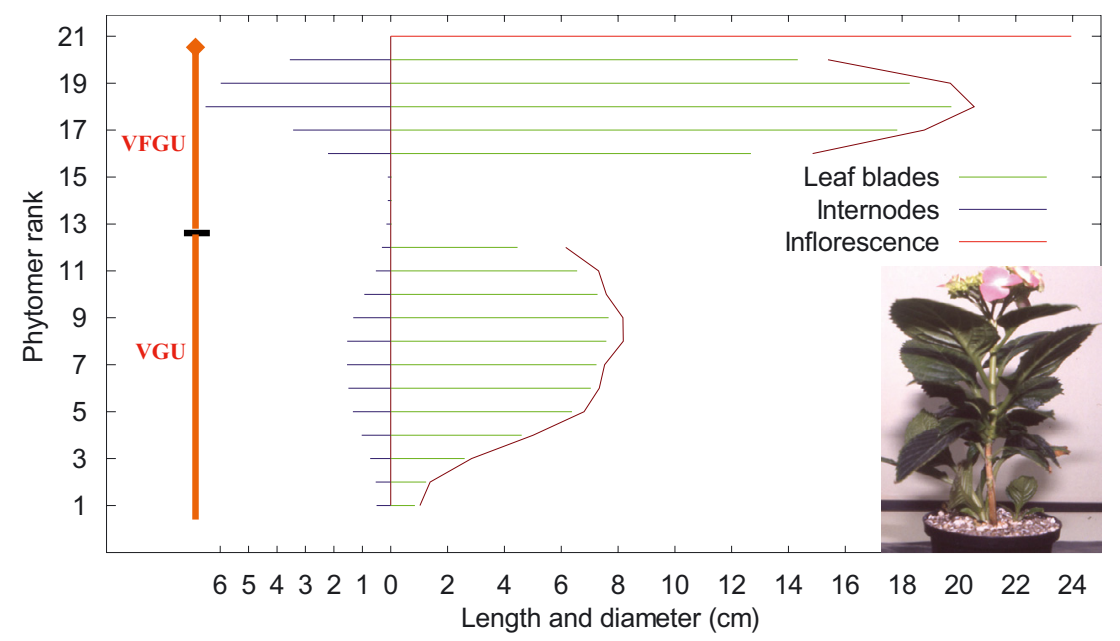

Figure 5. Morphological diagram of the architectural unit (Exp1). Distribution of the length of internodes, the length of leaf blades and the diameter of the inflorescence on the different phytomers of the axis. (A color version of this figure is available at www.forest.org.)

Analysis of the growth dynamics of the axis, leaves and the inflorescence enable us to identify four phases: a first phase, up to the 56th d, characterised by the continuous growth of the axis and leaves; the second phase from the 56th $d$ to the 140th d, distinguished by an apparent growth arrest; the third phase, corresponding to the cold treatment at $2{ }^{\circ} \mathrm{C}$ (from the 145 th to the 258th d); and the fourth phase, characterised by the rapid growth of preformed organs in the buds (internodes, leaves and inflorescence) up to the terminal floral bloom (Fig. 4).

\subsection{Description of the architectural unit}

The organogenesis and the growth of organs lead to the morphogenesis of the architectural unit whose components are represented on a morphological diagram (Fig. 5). If we study it from the base to the end of the axis, we can see a first set of phytomers whose leaves progressively increase in length and then stabilise (at the eighth phytomer), before rapidly decreasing. The length of the internodes follows a similar evolution. We then see three scaly phytomers (from the 13 th to the 15th rank), without assimilative blade, where the internodes are practically non-existent. They are followed by five leaf phytomers whose blades and internodes are quite big, and whose size varies according to a Gaussian-type curve. Finally, in the distal position, the last phytomer bears the inflorescence.

The architectural unit consists of a morphogenetic unit and two growth units. The first growth unit, referred to as the Vegetative Growth Unit (VGU), develops from day 1 to day 60 . It is the result of the initiation of phytomers that make up the stem and of their immediate elongation. This VGU is a neoformed growth unit. The second growth unit, referred to as the Vegetative and Floral Growth Unit (VFGU), consists of two phases. The first phase corresponds to the preformation of the vegetative and then the floral primordia without growth (from the 60 th to the $152 \mathrm{nd} \mathrm{d}$ ), and the second phase (from the $252 \mathrm{nd} d$ to the 311 th $\mathrm{d}$ ) corresponds to the growth of preformed organs. This VFGU is a preformed growth unit. The intermediary period (from the 152 nd to the $252 \mathrm{nd} d$ ) corresponds to the arrest of meristem activity and to a dormancy period. The morphogenesis unit that corresponds to the organogenic activity of the meristem therefore develops between day 1 and day 152 .

\subsection{Analysis of the morphological diagram of plants grown under contrasting environmental conditions}

Analysis of the morphological diagram of plants and the growth dynamics of the organs of plants grown under two environmental conditions that are in contrast with and distinct from those of Exp1 reveal major differences. The experimental conditions of Exp2 are characterised by a constant photoperiod of $16 \mathrm{~h}$ and a constant temperature of $22{ }^{\circ} \mathrm{C}$ (Fig. 2). Under these conditions, the morphological diagram of the plants presents, from the base to the end of the axis, a series of phytomers for which leaf length progressively increases and than stabilises at a value of approximately $15 \mathrm{~cm}$ between phytomers 8 to 21 , before decreasing once again up the last phytomer (Fig. 6). Growth dynamics, measured by the length of the axis and the leaf surface, is continuous (Fig. 7). Organogenesis, measured by the number of phytomers, is also continuous with an apparent plastochron of $6.3 \mathrm{~d}$. During the course of this long growing period $(225 \mathrm{~d})$, the continuous growth of neoformed metamers leads to the formation of a vegetative growth unit (VGU) consisting of a large number of metamers. Observation of the apical bud on the plants at this stage of development revealed the presence of three phytomer primordia, characteristic of vegetative organogenesis, and the absence of floral organs. The plant is maintained in the neoformation growth phase (Phase 1). The experimental conditions of Exp3 are characterised by an increasing photoperiod at the beginning of growth of 12 to $16 \mathrm{~h}$ and a daily temperature ranging from 16.5 to $24.5^{\circ} \mathrm{C}$ (Fig. 2). Under these conditions, the development of the architectural unit until floral bloom takes 


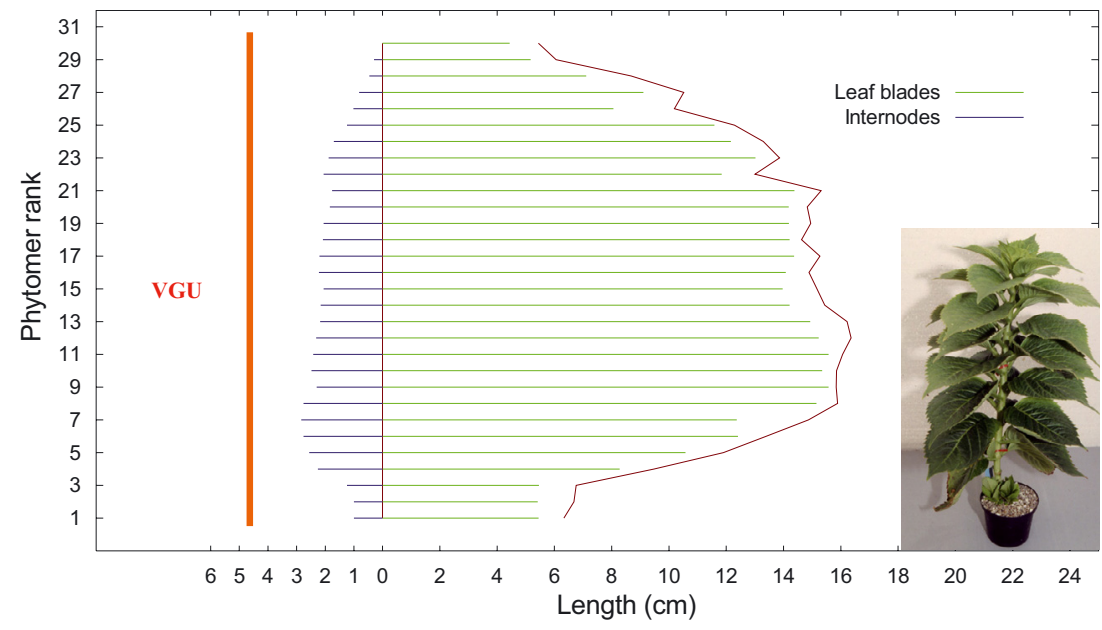

Figure 6. Morphological diagram of the architectural unit (Exp2). Distribution of the length of internodes, the length of leaf blades and the diameter of the inflorescence on the different phytomers of the axis. (A color version of this figure is available at www.forest.org.)

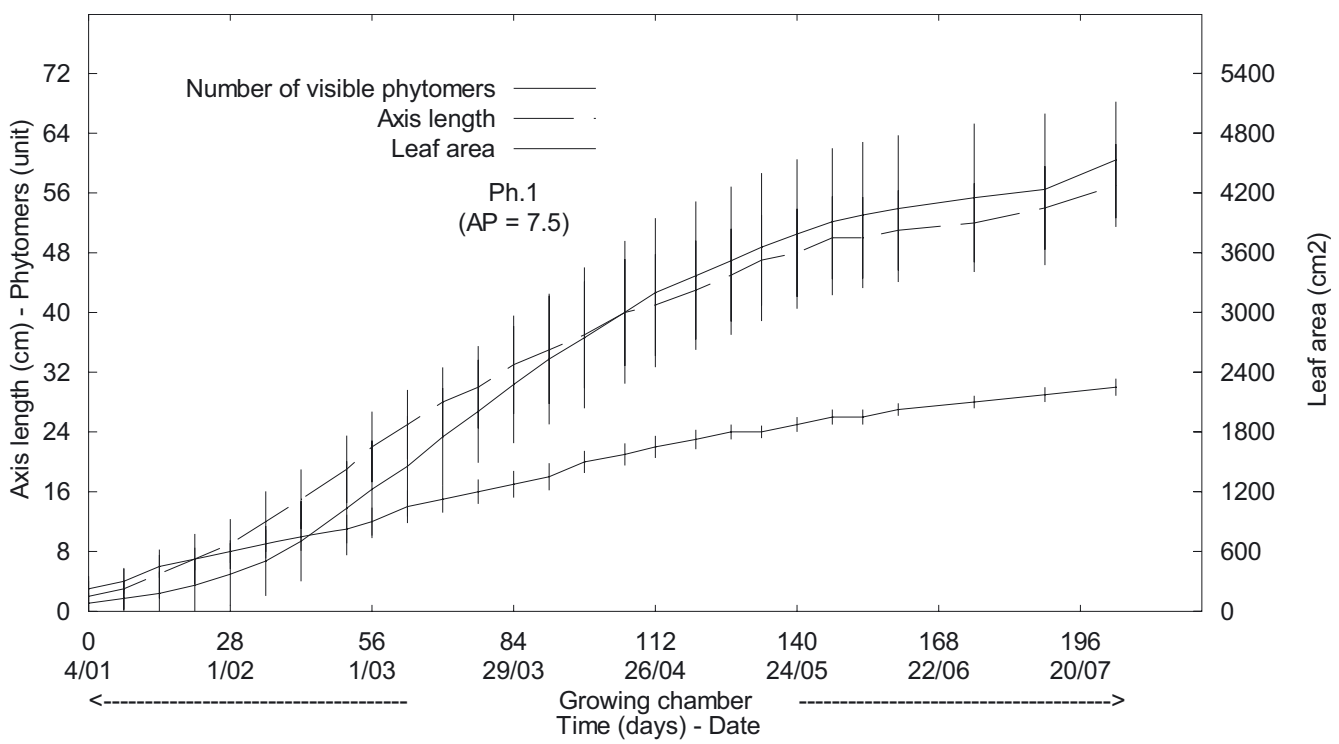

Figure 7. Growth dynamics of the different organs during the formation of the architectural unit (Exp2). Number of visible phytomers; axis height $(\mathrm{cm})$ and leaf area $\left(\mathrm{cm}^{2}\right)$.

place over $125 \mathrm{~d}$. As of the 6th metamer, the morphological diagram shows a progressive increase of the length of the leaves and a sharp decrease at the 7 th metamer (Fig. 8). From the 8th to the 14th metamer, the length of the leaves increases and then gradually decreases. The stem carries the inflorescence in the terminal position. At the beginning of growth, growth dynamics very rapidly reveal a stabilisation of the number of visible phytomers, followed by a continuous increase as of the 35 th $\mathrm{d}$ (Fig. 9). Measurement of the length of the axis reveals similar development. The leaf surface shows a continuous increase as of the beginning of growth until the 105th d; it then stabilises. The growth of the inflorescence, measured by its diameter, begins on day 70 and continues until flowering. During the first $15 \mathrm{~d}$ of growth, the continuous growth of neoformed metamers leads to the formation of a vegetative growth unit (VGU), consisting of a small number of metamers (Phase 1). It is followed by a period of slow growth, limited to an increase of the leaf surface of pre-existing leaves (Phase 2). A continuous growth phase begins as of the 35 th $\mathrm{d}$, leading to the formation of the vegetative and floral growth unit (VFGU). Phase 3, identified in Exp1 and corresponding to a dormancy period, is not observed under these experimental conditions (Fig. 9).

\section{DISCUSSION}

The quantitative and dynamic analysis of the organogenesis and growth of $H$. macrophylla requires a large number of measurements, some of which are destructive. Data quality was ensured by the homogeneity of young plants resulting from asexual and clonal reproduction using mother microplant culture. This work allowed us to show that the construction of 


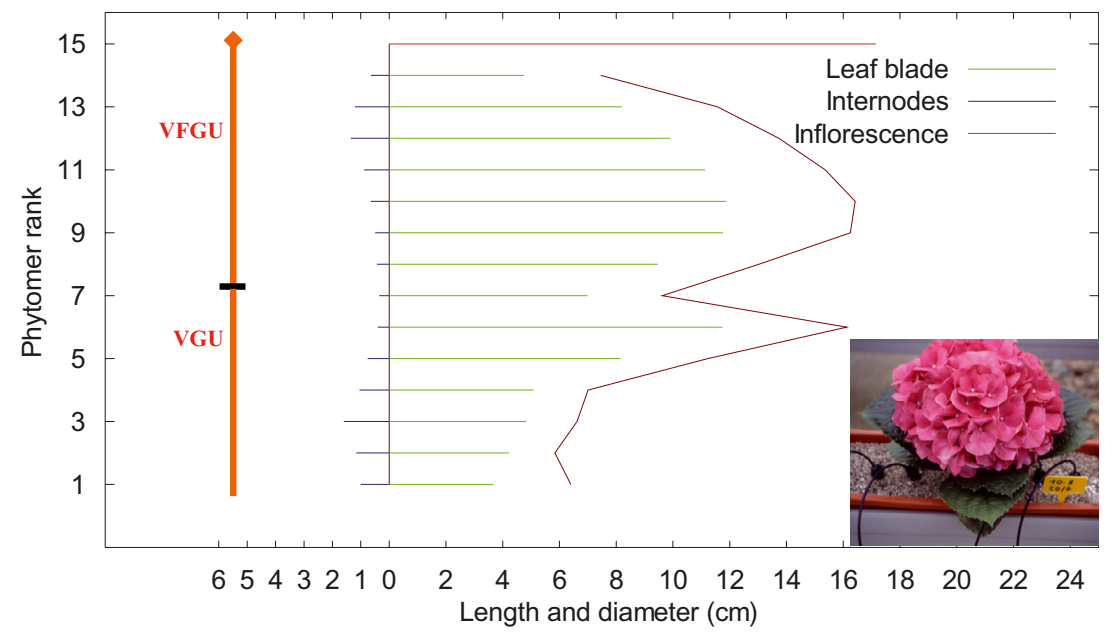

Figure 8. Morphological diagram of the architectural unit (Exp3). Distribution of the length of internodes, the length of leaf blades and the diameter of the inflorescence on the different phytomers of the axis. (A color version of this figure is available at www.forest.org.)

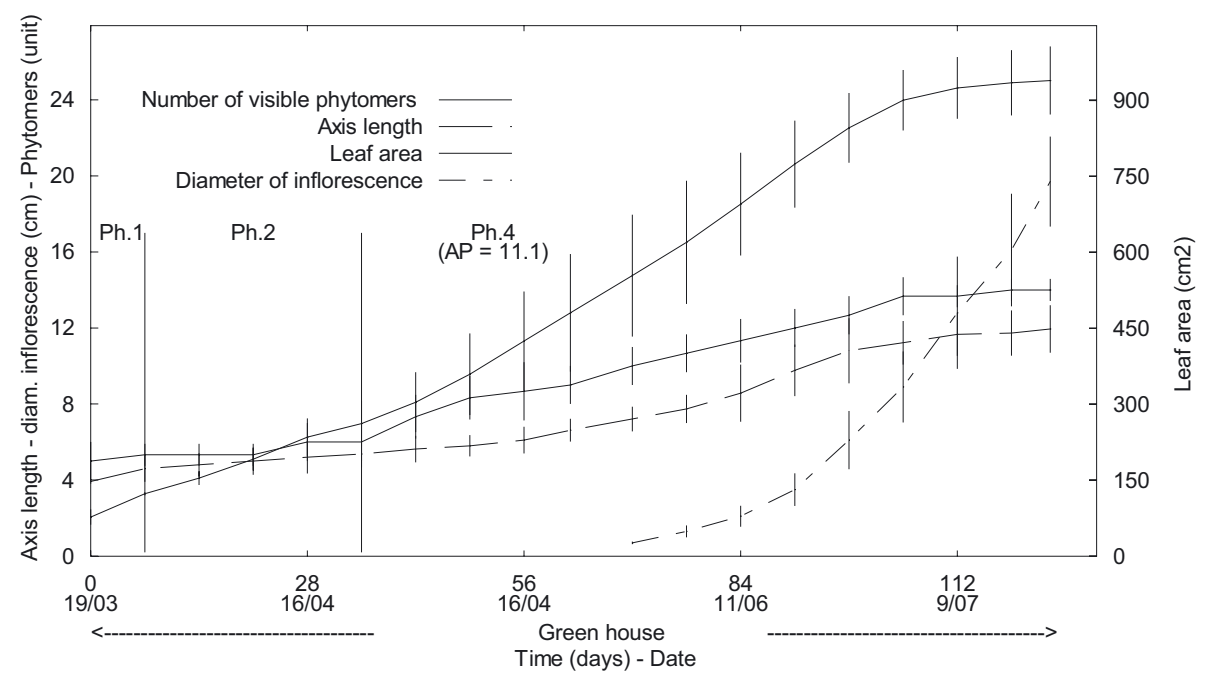

Figure 9. Growth dynamics of the different organs during the formation of the architectural unit (Exp3). Number of visible phytomers; axis height $(\mathrm{cm})$, leaf area $\left(\mathrm{cm}^{2}\right)$ and diameter of inflorescence $(\mathrm{cm})$.

a flowering axis is characterised by a morphogenesis unit as defined by Hallé and Martin (1968) and two growth units. It is therefore possible to propose a schematic description of the architectural unit of $H$. macrophylla with these two growth units (VGU and VFGU), broken down into four successive development sequences (Fig. 10).

Sequence A, referred to as "Organogenesis and vegetative growth", is characterised by the immediate elongation of phytomers formed by the terminal meristem (neoformation growth; Guedon et al., 2006); it corresponds to the formation of the VGU.

Sequence B, referred to as "Floral transformation", includes the various processes that lead to the transition from vegetative organogenesis to inflorescential organogenesis at the apical level. It begins with a sub-sequence, B1, during which vegetative organogenesis occurs without elongation and with the for- mation of a vegetative bud (vegetative preformed primordia). All of the scale and leaf phytomers of the VFGU are formed during this sub-sequence. It therefore has to take place before floral initiation (B2) and the beginning of inflorescential organogenesis (floral preformed primordia) (B3). Dormancy establishes itself during this sub-sequence (B3). The mixed bud is formed at the end of sequence $\mathbf{B}$.

Sequence $\mathbf{C}$, referred to as "Dormancy and breaking of dormancy", does not present any apparent morphological modifications.

Sequence D, referred to as "Development and floral bloom", corresponds to the elongation of preformed vegetative and floral organs in the mixed bud.

These results, whose originality lies in the integration of the entire formation of the flowering axis, are discussed for 


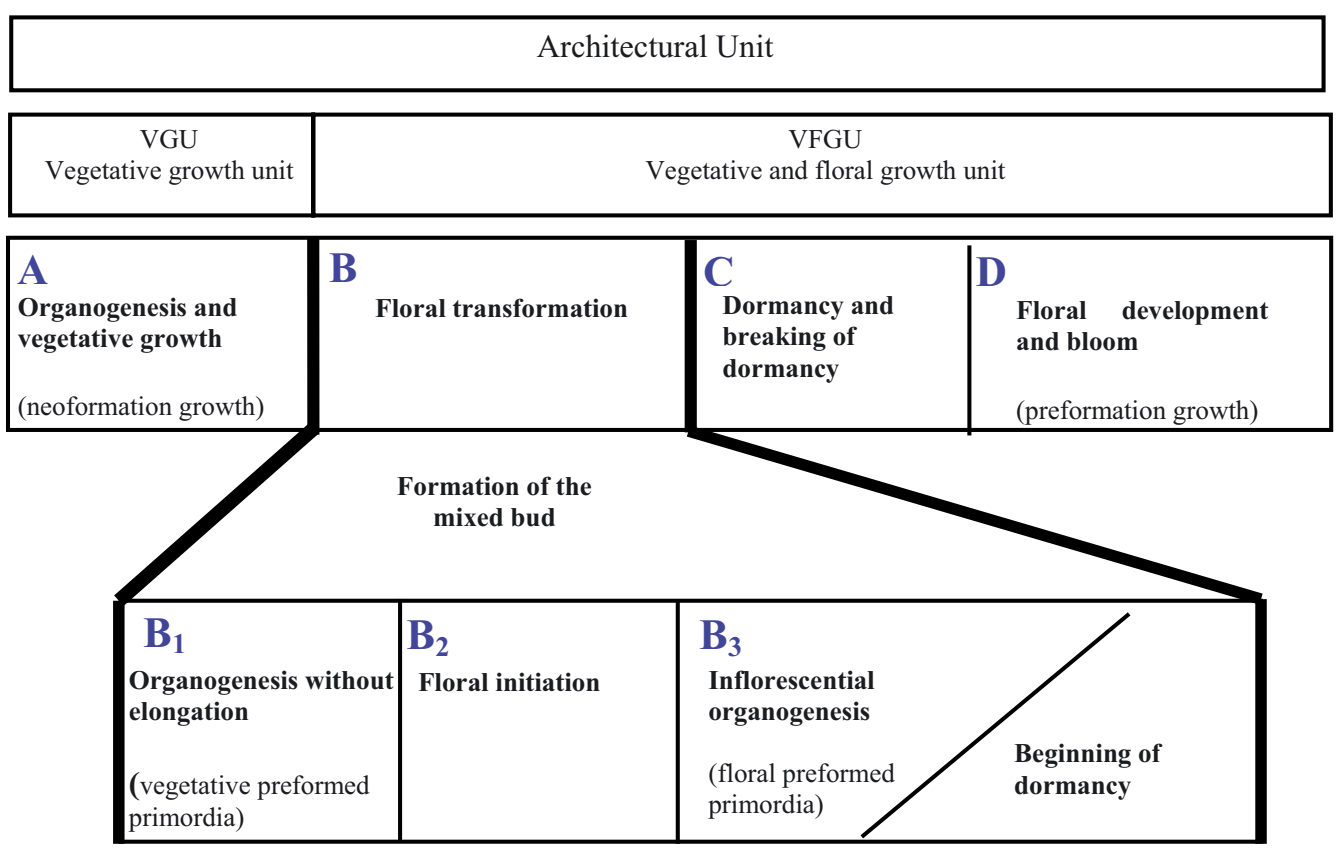

Figure 10. The development sequences of the architectural unit of $H$. macrophylla.

the four development sequences (A, B, C and D) in relation with the effect of environmental factors.

Sequence A presents a large spatial variability because the number of leaf phytomers varies from 7 to 30 , depending on the different experimental climatic environments. After the formation period for young plants under conditions involving a long photoperiod and high temperatures, the plants exposed to a long photoperiod during the entire length of the experiment (Exp2) maintained continuous growth and organogenesis with the formation of a single growth unit (VGU). In this conditions, the number of formed phytomers seems not inhibit continuous neoformed growth. This behaviour is different in other species for which the number of elongated leaves inhibits vegetative organogenesis and stem growth (Champagnat et al., 1986). Zhou and Hara $(1988 ; 1989)$ analysed the formation of the vegetative axis that corresponds to the growth of organs newly formed from a latent axillary bud. They reveal a leaf growth and emergence profile similar to our observations and define an apparent plastochron ranging from 5 to $20 \mathrm{~d}$. By distinguishing growth organogenesis, the separation of sequences $\mathbf{A}$ and $\mathbf{B}$ makes it possible to calculate the identical true and apparent plastochrons equal to $7.7 \mathrm{~d}$ for sequence $\mathbf{A}$, and an apparent plastochron of $18.9 \mathrm{~d}$ for sequence $\mathbf{B}$, with arrest of vegetative organogenesis (Figs. 3 and 4).

Sequence $\mathbf{B}$ plays an essential role in the construction of the architectural unit. It depends on the effect of flowering induction factors, especially temperature and photoperiod (Bailey, 1989). It corresponds to the first visible exterior marker of the floral transition and to the formation of a mixed bud. The three phenomena which take place during sequence $\mathbf{B}$ (the formation of the mixed bud, the development of the inflorescential mixed bud and the onset of dormancy) must be discussed separately.
The formation of the mixed bud is influenced by environmental factors (Bailey, 1989), but it also seems to depend on endogenous factors such as the size of the plant, the number of phytomers and nutritional balances (Levy and Dean, 1998). We were therefore able to show a different sensitivity to these induction factors on the basis of genotype, type of axis (terminal or axillary), and the number of phytomers that make up the axis (Adkins et al., 2003; Orozco-Obando et al., 2005). In this study, the homogeneity of young plants, grown in unistem mode, allowed us to analyse the morphological components of sequence $\mathbf{B}$ with a low level of variability. Our study shows that the photoperiod is the major environmental factor in the formation of mixed bud. A short but increasing photoperiod (from 12 to $14 \mathrm{~h}$ ) with a average temperature close to $20{ }^{\circ} \mathrm{C}$ inhibits partially internode elongation but not leaf elongation (Ph. 2 of Exp3, Fig. 9). In this case, floral induction takes place very early in the plant development, limiting significantly the vegetative organogenesis. A short and decreasing photoperiod (from 13 to $8 \mathrm{~h}$ ) with a decrease temperature (from 20 to $8{ }^{\circ} \mathrm{C}$ ) inhibits totally internode and leaf elongation (Ph. 2 of Exp1, Fig. 4). In this case, floral induction takes place after a long period of vegetative organogenesis.

Our study shows that the vegetative organogenesis sequence without elongation (B1) occurs before floral initiation and that it corresponds to the formation of a relatively constant number of phytomer primordia ( 7 to 8 ). It would appear that this accumulation of primordia at the apical level plays a role in floral initiation. We can hypothesize that there is a "point of no return", at which the floral transformation process is set in motion and is irreversible, as was shown for herbaceous plants (Bernier, 1989). If this point does exist and if it can be identified, then research must be focused on the vegetative organogenesis phase without elongation (B1). 
The development of the inflorescential mixed bud is the second phenomenon of floral transformation. By monitoring it, we were able to identify the successive floral stages (Galopin et al., 2008; Uemachi and Nishio, 2000). Observation of these stages serves as a reference for crop management with, for example, the triggering of the cold chamber entry date to artificially break dormancy. If a constant number of leaf primordia is observed in the bud before floral initiation, this could then act as a useful indicator for the management of induction factors. The accumulation of young leaves at the apical level, up to a maximum number and with very limited growth, appears to play a progressive inhibition role of the vegetative meristem, leading to the progressive initiation of floral transformation and the onset of dormancy. Champagnat (1992) revealed this phenomenon by showing that the removal of young leaves significantly delays the onset of dormancy. If the application of this type of ablation in Hydrangea actually delayed floral transformation, we could then better identify the importance of stage B1 in apical functioning.

The third phenomenon that characterises floral transformation is the onset of dormancy. During sub-sequence B3, it is partly associated with the natural decrease of the photoperiod and temperatures; however, these conditions are also favourable to floral induction (Wallerstein, 1981). For certain cultivars with recurrent flowering, the axillary buds of the middle portion of the vegetative unit present vegetative development, floral transformation and continuous flowering without dormancy during the same growing season, (Adkins et al., 2003). These observations lead us to hypothesize that sensitivity to induction factors may differ according to genotype. A differentiation between flowering induction factors and dormancy induction factors could therefore be observed. In this study, we observed both the presence and the absence of dormancy for the same genotype. The gradual decrease of the photoperiod (Exp. 1) led to the formation of a mixed bud approximately $60 \mathrm{~d}$ after the beginning of the experiment, with a pronounced arrest of growth. This arrest of growth induces the formation of scales, that protect the bud, and the onset of dormancy (Fulford, 1965, 1966). The number of pairs of scale leaves observed can then serve as a quantitative indicator of dormancy intensity. An increasing photoperiod from 12 to a maximum of $16 \mathrm{~h}$ (Exp3) leads to the formation of a mixed bud without scales and the maintenance of minimal leaf growth. Under these conditions, there is no onset of dormancy. Two distinct growth units could be observed (VGU and VFGU) whose growth rhythm is reduced to a fluctuation of the leaf growth. Our results show, for the first time, the absence of dormancy under conditions of increasing photoperiod (from 12 to $16 \mathrm{~h})$.

The sequence $\mathbf{C}$ exists under certain environmental conditions (Exp1). The presence of dormancy is accompanied by the evolution of primordia into protective scale leaves on the outside of the mixed bud. A cold treatment is necessary to break the dormancy. The absence of dormancy under other conditions (Exp3) does not justify cold treatment allowing to reduce the growing duration and to introduce a wide temporal variability.
The sequence D exists only under certain environmental conditions (Exp1 and Exp3). The vegetative and floral development observed during the sequence $\mathbf{D}$ informs on the conditions of carrying out previous sequences. In Exp3, the long photoperiod at the end of phase 2 (more of $14 \mathrm{~h}$ ) favoured stem growth, probably simultaneously with the continuation of floral organogenesis. Therefore we can think that there is a competition between floral organogenesis and vegetative growth showing a leaf area and an axis length shorter than in Exp1.

In this study, the analysis of phenotypic variation is limited to only three different climatic environments. It would therefore be advisable to extend this study to cover a wider range of environmental diversity, in order to assess the phenotypic variability, on the one hand, and to provide us with a better understanding of the influence of the different environmental factors on plant development, on the other. Subsequent to the work of Bailey and Weiler (1984), it would be interesting to test the effect of a temperature range of 15 to $18{ }^{\circ} \mathrm{C}$ with two photoperiods ( 8 and $16 \mathrm{~h}$ ) by carefully applying them to the two sub-sequences of vegetative organogenesis without elongation (B1) and of floral initiation (B2). This would make it possible to distinguish between the effects of temperature and photoperiod on floral transformation, on the one hand, and on dormancy, on the other, for the first time. The comparison of all the phenotypic changes observed would then allow us to assess the phenotypic plasticity of $H$. macrophylla. This would enable us to explain the adaptation of this species to highly contrasted climates, ranging from temperate to maritime tropical (for example, Guadeloupe, Basse-Terre, personal observation) and to analyse the possible evolution of its range of adaptation within a context of climate change.

Acknowledgements: We are grateful to R. Gardet, G. Céril and M. Laffaire for their technical assistance and to Gail Wagman for the English translation of the text.

\section{REFERENCES}

Adkins J.A., Dirr M.A., and Lindstrom O.M., 2003. Cold hardiness estimates for ten hydrangea taxa. Acta Hortic. 618: 163-168.

Bailey D.A. and Weiler T.C., 1984. Stimulation of Inflorescence expansion in florists' Hydrangea. J. Am. Soc. Hort. Sci. 109: 792-794.

Bailey D.A., Weiler T.C., and Kirk T.I., 1986. Chemical stimulation of floral initiation in florists' hydrangea. HortScience 21: 256-257.

Bailey D.A., 1989. Hydrangea production. Growers Handbook series, Timber press, Portland, Vol. 3, 91 p.

Bernier G., 1989. Control of floral induction and morphogenesis. C.R. Acad. Agric. Fr. 75: 3-10.

Cameron R.W.F., Harrison-Murray R.S., Atkinson C.J., and Judd H.L., 2006. Regulated deficit irrigation - a means to control growth in woody ornamentals. J. Hortic. Sci. Biotechnol. 81: 435-443.

Caraglio Y., 1986. Apparition du port buissonnant chez certains Ficus, Naturalia Monspeliensia, Colloque international sur l'arbre 1986, Montpellier, pp. 125-137.

Cayeux H., 1937. L'Hortensia en culture uniflore. Revue Horticole 16: 475-476.

Champagnat P., Barnola P., and Lavarenne S., 1986. Quelques modalités de la croissance rythmique endogène des tiges chez les végétaux 
ligneux. Naturalia Monspeliensia, Colloque international sur l'arbre 1986, Montpellier, pp. 279-302.

Champagnat P., 1992. Les bourgeons et le froid : notions indispensables. In : Côme D., Le froid et les végétaux, Hermann Editeurs des sciences et des arts, Paris, pp. 179-201.

Codarin S., Galopin G., and Chasseriaux G., 2006. Effect of air humidity on the growth and morphology of Hydrangea macrophylla L. Sci. Hortic. 108: 303-309.

Dugardin C. and Balemans L., 1991. Forcing of hydrangea with artificial supplementary lighting. Verbondsnieuws voor de Belgische Sierteelt 35: $135-137$.

Edelin C., 1986. Stratégie de réitération et édification de la cime chez les conifères. Naturalia Monspeliensia, Colloque international sur l'arbre 1986, Montpellier, pp. 139-158.

Fuchigami L.H. and Wisniewski M., 1997. Quantifying bud dormancy: physiological approaches. HortScience 32: 618-623.

Fulford R.M., 1965-1966. The morphogenesis of Apple buds. I-IV, Ann. Bot., 29: 167-180, 30: 25-38, 209-219, 597-606.

Galopin G., 1995. Biologie du développement d'Hydrangea macrophylla. Caractérisation du potentiel morphogénétique et maitrise de ses expressions par les conditions de culture. Thèse de Doct. Phys. Vég., Univ. Clermont-Ferrand, 97 p.

Galopin G., Beaujard F., and Gendraud M., 1996. Intensive production of juvenile cuttings by mother microplant culture in Hydrangea macrophylla "Leuchtfeuer". Can. J. Bot. 74: 561-567.

Galopin G., Codarin S., Viemont J.D., and Morel Ph., 2008. Architectural development of inflorescence in Hydrangea macrophylla $\mathrm{cv}$ Hermann Dienemann. HortScience 43: 361-365.

Guedon Y., Puntieri J.G., Sabatier S., and Barthélémy D., 2006. Relative extents of preformation and neoformation in tree shoots: Analysis by a deconvolution method. Ann. Bot. 98: 835-844.

Guo Z., Goi M., Tanaka M., and Fukai S., 1995. Effects of temperature and photoperiod on the bud formation of Hydrangea. Technical bulletin of faculty of agriculture, Kagawa University 47: 23-31.

Hallé F. and Martin R., 1968. Etude de la croissance rythmique chez l'hévéa (Hevea brasiliensis Müll.-Arg., Euphorbiacées Crotonoïdées). Adansonia Sér. 2, 8: 475-503.

Joustra M.K., 1989. Application of growth regulators to ornamental shrubs for use as interior decoration. Acta Hortic. 251: 359-368.

Levy Y.Y. and Dean C., 1998. The transition to flowering. Plant Cell 10: 1973-1989.
Littlere B. and Strømme E., 1975. The influence of temperature, day length and light intensity on flowering in Hydrangea macrophylla (Thumb.) Ser. Acta Hortic. 51: 285-298.

Morel Ph., 2001. Growth control of Hydrangea macrophylla through water restriction. Acta Hortic. 548: 51-58.

Morita M., Iwamoto S., and Higuchi H., 1980. Interrelated effect between Thermo- and Photo-periodism on growth and development of Ornamental Woody plants V. Modification of photoperiodic response to temperature treatment in Hydrangea. J. Japan. Soc. Hort. Sci. 48: 488-494.

Morita M. and Osuka M., 1981. Effects of gibberellin on growth and development of Hydrangea. Research Bulletin of the Aichi-Ken Agricultural Research Center. 13: 228-234.

Orozco-Obando W., Hirsch G.N., and Wetzstein H.Y., 2005. Genotypic variation in flower induction and development in Hydrangea macrophylla. HortScience 40: 1695-1698.

Post K., 1942. Effects of daylength and temperature on growth and flowering of some florist crops. Cornell University Agricultural Experiment Station Ithoca, New York, 787: 45-52.

Rusch K., Leinfelder J., and Rober R., 1987. Growth retardants in Hydrangea forcing. Deutscher Gartenbau 41: 216-218.

Sauvage G. and Chevalier C., 1943. Hydrangea et Hortensia, Monographie - Historique, culture commerciale et d'amateur. Editorial office Wauthoz-Legrand, Bruxelles, 123 p.

Shanks J.B., Mityga H.G., and Douglass L.W., 1986. Photoperiodic responses of Hydrangea. J. Am. Soc. Hort. Sci. 111: 545-548.

Sieben J., 1978. A great demand for smaller hydrangeas. Vakblad voor de Bloemisterij 33: 25.

Uemachi T. and Nishio T., 2000. Inflorescence development in Hydrangea macrophylla. Acta Hortic. 515: 265-271.

Vidalie H., 1986. Influence of various cold treatments on the reaction to forcing of miniature Hydrangea macrophylla. Acta Hortic. 181: 263-266.

Wallerstein L., 1981. The nature of dormancy in Hydrangea macrophylla. Hassadeh 61: 1846-1848.

Yeh D.M. and Chiang H.H., 2001. Growth and flower initiation in Hydrangea as affected by root restriction and defoliation. Sci. Hortic. 91: 123-132.

Zhou T.S. and Hara N., 1988. Development of shoot in Hydrangea macrophylla I. Terminal and axillary buds. Bot. Mag. Tokyo 101: 281-291.

Zhou T.S. and Hara N., 1989. Development of shoot in Hydrangea macrophylla II. Sequence and timing. Bot. Mag. Tokyo 102: 193-206. 